nearly three times the 1939 price and paper is almost five times the pre-war figure. A sample survey made by the Publishers Association in 1953 put these three items at 28 per cent of the published price of general books and fiction, and at the beginning of 1956 many publishers received notice of a 15 per cent increase in printing charges. Book printing is only about 8 per cent of the total output of printing in Britain and has to compete with larger and more profitable custom. Large editions are now the order of the day wherever possible, and it has been suggested that the main hope for economy in binding lies in the reduction of the number of processes by use of thermoplastic adhesives in place of sewing and in greater standardization.

Most new books are subject to the Net Book Agreement and a discount of $33 \frac{1}{3}$ per cent is commonly allowed to booksellers on fiction and general books, with up to 25 per cent on specialized technical, legal and medical books. Even with the former, many booksellers claim it is almost impossible to pay their way on new books, and throughout 1955 the book trade was obliged to concentrate on the problem of the wholesaler. When Simpkin Marshall, Ltd., ceased trading on March 30, 1955, a serious gap was created in the distributive machinery of the book trade, which has not yet been filled. 'The Net Book Agreement was modified in the first National Book Sale of February 1955, and this successful experiment was repeated in 1956.

Educational publishing is a highly specialized section of the trade with which about 80 members of the Publishers Association are concerned. Expenditure on books by the $\mathbf{5 7 7}$ public library authorities increased from $£ 2,305,000$ in $1950-51$ to $£ 3,180,000$ in 1954-55, partly owing to increased prices. Most business is still done through bookshops, and a survey of readers' methods of selecting their books carried out by Harrap last year indicated the importance of reviews. There is a general impression that the traditional book market is changing fast and annual analyses made by The Bookseller indicate that books on trade, industry and commerce are now nearly eight times the pre-war figure and increased by more than 50 per cent in 1955 alone. Technical handbooks are nearly treble the pre-war figure, as are topographical books, and books on art and architecture have more than doubled. Fiction is now only 18.5 per cent of the total compared with 30 per cent in 1937, although it still forms the largest section.

\section{BRITISH VITAL STATISTICS FOR 1953}

$\mathrm{T}$ HE General Register Office has recently published the text commentary on the vital statistics of 1953 (Registrar General's Statistical Review of England and Wales for the Year 1953. Text volume. Pp. xv+250. H.M.S.O., 1956. 9s.). It follows the traditional pattern associated with these volumes and contains sections dealing with the total population, fertility, marriage and divorce and mortality. No noticeable changes occurred in 1953. Births were fractionally larger than in the previous year, and the fertility rates were just sufficient for population replacement. The increase in fertility was mainly concentrated at marriages of medium duration, which had taken place between 1948 and 1953, but the authors do not believe that these slight increases herald any change in completed family size.

The total number of marriages has decreased, but this is largely due to the depletion of the number of unmarried people in the population. When related to the unmarried, the marriage-rate remains high, and is about 10 per cent above the pre-war level, and there is a continuing increase in marriages at younger ages. As a result of the high marriage-rates in the past, the ratio of married women aged 15-49 to all women in that age group has reached a record value of 678 per thousand. Divorces appear to be running at about 30,000 per year, and the re-marriagerate of divoreed persons remained high.

Deaths are now increasing because of the increasing number of old persons in the population, though mortality-rates remain constant. The excess of male mortality over female is growing, particularly at ages between 45 and 85 . Infant mortality has fallen slightly, but geographical differentials persist both for infant and adult deaths. Particular attention is given to deaths from tuberculosis and cancer, and it is gratifying to see that the decline in the tuberculosis death rate is continuing.

Perusal of the volume as a whole suggests that the experience of 1953 affords no reason to change previous assessments of the demographic situation of England and Wales.

\section{THE UNIVERSITY COLLEGE OF RHODESIA AND NYASALAND}

$G \mathrm{OR}$ eleven years, various groups, which often 7 included Africans and Asians, worked, publicized and collected money in East Africa until, as a result of their efforts, nearly half a million pounds was available for the creation of a University College for Rhodesia and Nyasaland at Salisbury. The first groups of buildings have now reached roof height; the arts building and the science research laboratories are nearly complete.

The twelve heads of departments are in Salisbury and at first were concerned with the preliminary planning and equipping of these buildings. Now they have begun to establish their research work; it is a happy circumstance that enables the University College to establish its research activities before its teachers have to receive its first undergraduate students.

The Federation of Rhodesia and Nyasaland, because it is advancing in so many directions at once, offers immense possibilities for research workers in every field of knowledge. This work will be added to the great volume of research already taking place in the Federation; this is undertaken by government departments, industrial and commercial undertakings or special research institutes. The main research projects have been described by the viceprincipal, Prof. B. A. Fletcher (Universities Rev., 29, No. 1).

The more specialist or long-term researches will be undertaken at the University College. An experimental garden of ten acres has been prepared on the University site in order to make possible work in experimental taxonomy. This work will coincide with the preparation, under government sponsorship, of a Flora of the Federation; special attention will be given to those groups difficult to classify by orthodox methods. 